\title{
Immunoglobulin Joining Region
}

National Cancer Institute

\section{Source}

National Cancer Institute. Immunoglobulin Joining Region. NCI Thesaurus. Code C13243.

The portion of the light and heavy chains of immunoglobulin molecules where the variable and constant regions meet. 